\title{
Comunicação, linguagem e representações sociais: análise do gênero jornalístico televisivo
}

\author{
Heloisa Juncklaus Preis Moraes \\ Universidade do Sul de Santa Catarina - heloisapreis@hotmail.com \\ Doutora em Comunicação Social. Professora do Programa de Pós-Graduação em Ciências da Linguagem.
}

João Paulo Dagoberto de Luca Júnior

Universidade do Sul de Santa Catarina - juninhodeluca@hotmail.com Jornalista. Mestrando do Programa de Pós-Graduação em Ciências da Linguagem.

\begin{abstract}
Resumo
Já há várias décadas a Teoria da Comunicação, assim como outras importantes correntes teóricas, reconhece o caráter subjetivo do receptor da mensagem. No entanto, embora cada pessoa receba as informações de forma diferente, o público - ou a audiência, como prefere Aristóteles - continua se comportando como uma grande massa uniforme. Se cada pessoa recebe as informações de maneira diferente, como poderiam os Meios de Comunicação de Massa (MCM) controlar a pauta de debate público? Entretanto, isso ocorre com frequência e é objeto de estudo de Pierre Bourdieu (1992), com sua teoria sobre o habitus da comunicação. A discussão recai sobre a forma de produção textual do gênero jornalístico televisivo como um modo de construção de sentido para um maior número de receptores. No entanto, como hipótese, nos baseamos na ideia de que essas informações não são suficientes para uma reflexão aprofundada dos assuntos apresentados. Comparamos notícias veiculadas pelo Jornal Nacional (Rede Globo de Televisão) sobre o tema "Copa do Mundo FIFA", no dia 16 de junho de 2011, com as notícias veiculadas em outros meios de comunicação no mesmo período.
\end{abstract}

Palavras-chave

Comunicação. Linguagem. Representações Sociais. Telejornalismo. Gênero.

\begin{abstract}
It has already been several decades since the Theory of Communication, as well as other important theory perspectives, acknowledges the subjective nature of the message receiver. However, although each person perceives information in a different way, the public - or the audience, as preferred by Aristotle - continues behaving as a big homogeneous mass. If each person perceives information differently, how could the Mass Media (MCM) control the agenda of public debate? Nonetheless, this occurs very often and it is the object of study for Pierre Bordieu (1992) with his theory about the habitus of communication. This discussion focuses on the ways of textual production for the journalistic genre of television as a way of constructing meaning for a larger number of TV viewers. Yet, as a hypothesis, we rely on the idea that this information is not sufficient for a deeper reflection on the presented issues. Thus, we compare the news broadcasted by Jornal Nacional da Rede Globo de Televisão about "FIFA World Cup" on the 16 of June, 2011 with the news televised by other media in the same period.
\end{abstract}

\section{Keywords}

Communication. Language/Speech. Social Representations. TV Journalism. 
á uma íntima relação entre o campo jornalístico e o campo político. Pierre Bourdieu (1992), Noam Chomsky (2003) e, mais recentemente, Niklas Luhmann (2005) destacaram essas interações de duplo sentido entre os Meios de Comunicação de Massa e política. Podemos adicionar ainda nessa relação o campo econômico, constituindo uma tripla interação entre campos que, no entanto, constituem-se de maneira independente e diferente.

E, com base nos conceitos de habitus de Bourdieu, é possível elaborar o questionamento que irá direcionar esse trabalho: se as correntes hegemônicas da Teoria da Comunicação, da Teoria da Relevância, do sócio-interativismo bakhtiniano, etc., reforçam constantemente a condição singular do receptor da mensagem no processo comunicativo, incutindo sobre ele características particulares e subjetivas, como, ainda assim, os meios de comunicação de massa podem ser tão eficazes na construção e no controle da opinião pública? Em outras palavras, se somos todos seres socialmente diferentes, como é possível que as pessoas leiam ou assistam as notícias e interpretemnas de forma bastante próxima das interpretações dos demais?

O objetivo é tentar estabelecer o modus faciendi da construção da realidade a partir da linguagem dos Meios de Comunicação de Massa (MCM) e como isso afeta a democracia representativa. O problema, logo de início, é que o panorama da análise muda completamente quando desenvolvida no sentido $\mathrm{MCM}>$ democracia ou no sentido inverso, democracia $>$ MCM.

No primeiro caso, os meios de comunicação são tratados como essenciais para a existência da democracia representativa. A liberdade de informação e de opinião é uma condição sine qua non nas mais clássicas teorias do jornalismo e da democracia. Para escolher entre os mais capacitados para comandar a sociedade, a população precisa ter acesso às informações mais importantes que dizem respeito a praticamente todos os aspectos da vida social.

No segundo caso, considera-se a linguagem como elemento instrumental de construção da realidade. Um instrumento dos meios de comunicação. Por essa perspectiva, embora a liberdade de imprensa continue parecendo fundamental, o papel dos meios de comunicação enquanto organismo social de seleção das informações que serão veiculadas restringe e limita as informações que chegam à população, que deixa de ter acesso a todas as informações para ter acesso apenas às que os meios de comunicação consideram mais convenientes. 


\section{Mídia e sociedade}

Pressupondo a existência incontestável dessa relação quase simbiótica entre empresas jornalísticas, governo (via investimentos publicitários) e economia (via investimentos publicitários e financiamentos de campanhas), como não pensar em uma teoria conspiratória, tal qual denuncia Chomsky (2003) em sua obra de sociologia política, que determinaria aquilo que as pessoas devem pensar a respeito dos assuntos, quais os assuntos que serão veiculados e/ou abafados, etc.? Atendo-nos à relação entre campo jornalístico e campo político, a constatação inicial é que parece existir uma espécie de ciclo que flui dos meios de comunicação para o Governo e deste para os meios de comunicação. Por si só, essa relação dialógica já justifica um estudo mais aprofundado.

Toda ação do homem em sociedade possui, em menor ou maior grau, relevância social. Essas ações constituem primariamente os fatos sociais. A própria ausência de ação possui importância social. Essa relevância pode ser identificada como um valor-notícia. Ao longo dos anos, com as mudanças comportamentais das sociedades, os critérios de valor-notícia sofreram sensíveis mudanças, saltando entre o extraordinário, o insólito, a infração, o inesperado, a significância, a amplitude, a frequência, a negatividade, etc. Quanto mais valores-notícia forem identificados em um fato, maiores são as chances de que ele seja noticiado. Traquina (2005b, p. 77), a partir dos estudos do italiano Mauro Wolf, percebe que os valores-notícia estão presentes em todos os momentos da produção jornalística e os divide em duas grandes categorias: valores-notícia de seleção e valores-notícia de construção.

Além da teoria dos valores-notícia, existem ainda outras diversas teorias determinadas a explicar a lógica da seleção do que será ou não veiculado. Ao longo do século XX, elas constituíram o centro de estudos do jornalismo e, aos poucos, têm sido ajustadas à lógica dos valores-notícia. Mas uma delas, em específico, é bastante presente até o momento e fundamental para compreender a forma com a qual os meios de comunicação, por meio da linguagem, constroem a realidade social: o agendamento (ou agenda-setting).

A Teoria do Agendamento foi formulada por Maxwell McCombs e Donald Shaw na década de 1970. De acordo com este pensamento, a mídia determina a pauta (em inglês, agenda) para a opinião pública ao destacar determinados temas e preterir, ofuscar ou ignorar outros tantos. 
As ideias básicas da Teoria do Agendamento podem ser atribuídas ao trabalho de Walter Lippmann ${ }^{\text {ii }}$, um proeminente jornalista estadunidense. Ainda em 1922, Lippmann propôs a tese de que as pessoas não respondiam diretamente aos fatos do mundo real, mas que viviam em um pseudo-ambiente composto pelas "imagens em nossas cabeças". A mídia teria papel importante no fornecimento e geração destas imagens e na configuração deste pseudoambiente.

A fundamentação teórica de McCombs \& Shaw foi alicerçada originalmente por Bernard Cohen em 1963: "Na maior parte do tempo, [a imprensa] pode não ter êxito em dizer aos leitores o que pensar, mas é espantosamente exitosa em dizer aos leitores sobre o que pensar" (apud MCCOMBS \& SHAW, 1972, p.13).

A seleção dos fatos sociais que serão transformados em notícias e posteriormente veiculados caracteriza-se como o primeiro processo de edição. A ação de preterir um em relação ao outro limita a totalidade dos fatos sociais que chegam ao público - posteriormente ainda serão afetados por outros processos - como se outros fatos sociais excluídos nem mesmo existissem para a grande massa. É preciso reconhecer que a opção por oferecer publicidade a um ou outro fato social específico causa importante impacto na opinião pública. Por isso, diversos fatores mantêm tensionadas as pautas abordadas pelos MCM, como: linha editorial, alinhamento político-ideológico, resultados comerciais, interesses econômicos, etc. Esses interesses vão interferir no modo como as representações dos fatos sociais serão noticiadas, ou mesmo se serão veiculadas, ou ainda se serão excessivamente exploradas pelos veículos de imprensa.

Torna-se perceptível, já no processo de seleção, que são transmitidas ao público as informações consideradas de maior relevância, de acordo com os critérios de cada empresa jornalística; mas, em nenhum momento, são transmitidas todas as informações. E essa característica trará consequências importantes ao sistema democrático e ao processo eleitoral, devido à força que exerce sobre a opinião pública. Isso se nota claramente no pensamento de Luhmann, quando o sociólogo alemão coloca que “os meios de comunicação 'manipulam' a opinião pública. Eles perseguem interesses que não são veiculados juntos. Eles produzem ‘tendências"” (2005, p. 75).

\section{Mídia no Brasil}

Em março de 2010, o Governo Federal do Brasil divulgou o relatório consolidado da pesquisa Hábitos de informação e formação de opinião da população 
brasileira, executada pelo instituto Meta - Pesquisas de Opinião. O público-alvo foi formado por brasileiros, maiores de 16 anos, residentes em moradias particulares (próprias ou alugadas), em todo o território nacional (META, 2010, p. 3). A pesquisa entrevistou 12 mil pessoas proporcionalmente nas cinco regiões da federação (META, 2010, p. 5).

A pesquisa utilizou as proporcionalidades obtidas a partir do Instituto Brasileiro de Geografia e Estatística (IBGE) para determinar os percentuais de gênero, renda familiar, idade e escolaridade a serem utilizados pelos pesquisadores (META, 2010, p. 8). O resultado é um mapa detalhado dos hábitos da sociedade brasileira na formação de sua opinião e, como consequência, na construção de suas representações a respeito daquilo que é veiculado nos meios de comunicação.

De acordo com a pesquisa, a televisão é assistida por 96,6\% da população, enquanto que o rádio é ouvido por $80,3 \%$ iii. São números elevados, principalmente quando comparados com o hábito de leitura de jornais e revistas, 46,1\% e 34,9\% respectivamente.

No entanto, se o meio impresso atinge com eficácia uma parcela bastante específica da sociedade brasileira, o mesmo não pode ser afirmado em relação à mídia eletrônica, sobretudo a televisão, que impera no cotidiano das pessoas, com 96,6\% confirmando sua utilização. Destes, $83,5 \%$ assistem apenas as emissoras de canal aberto. O telejornal é a programação mais procurada, com $64,6 \%$ das respostas, embora seja preciso considerar que $68,8 \%$ dos brasileiros passam de uma a quatro horas por dia à frente da televisão. Esses dados comprovam o caráter de ubiquidade da mídia televisiva. Nas figuras 9, 10 e 11, surgem novos detalhes sobre o comportamento da população.

Novamente, esses números parecem sugerir uma relação direta de preferência da população de acordo com a região, já que, como no caso dos jornais, a distribuição da renda também ocorre de maneira desigual no país. Por isso mesmo, o principal meio de captação de sinal de TV é antena convencional: 56,3\% apontaram ser esse o meio de captação do sinal de TV em sua residência. A antena parabólica foi constatada em 30,3\% das respostas, estando no Nordeste o maior percentual: $41,5 \%$ dos entrevistados. A TV via cabo apresenta maiores percentuais no Sul e no Sudeste: $14,2 \%$ e 13,3\%, respectivamente (META, 2010, p. 22).

Apesar de serem percentuais expressivos, esses números não chegam exatamente a ser uma surpresa ao meio acadêmico, uma vez que a própria verificação 
empírica ou observacional do contexto social brasileiro já desenhava esse cenário. A exceção, talvez, sejam os percentuais de leitura, que parecem estar acima da media daquilo que se imaginava anteriormente. De todo modo, há ainda uma verificação muito importante na pesquisa, que poderia facilmente passar despercebida ou receber um grau de importância inferior ao que realmente possui: a força de produção e/ou inversão de opinião, característica que pode ser conferida nas imagens a seguir.

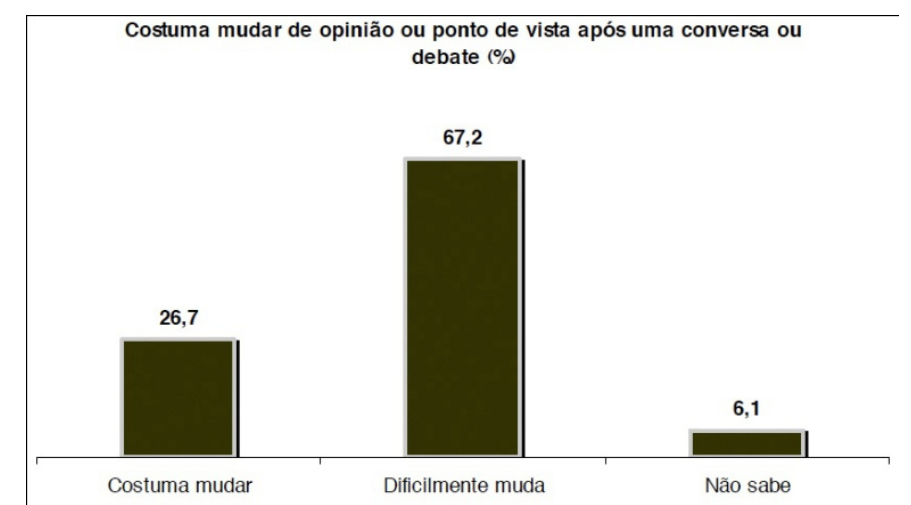

Figura 1 - Mudança de opinião em conversa com amigos Fonte: META, 2010, p. 19.

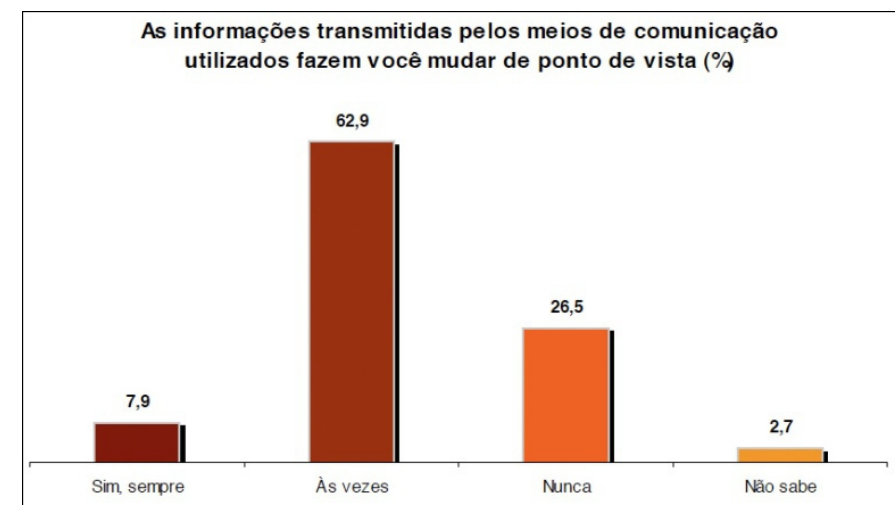

Figura 2 - Mudança de opinião a partir de informações dos MCM Fonte: META, 2010, p. 19.

Em uma leitura rápida, é perceptível que as pessoas tendem a mudar de opinião mais facilmente a partir de informações recebidas pelos Meios de Comunicação de Massa do que em conversas com os amigos, tendo eles, ou não, maior grau de conhecimento sobre o assunto. Isso ocorre por que os veículos de imprensa possuem, de alguma maneira, um caráter de autoridade. "A autoridade do sujeito que tem o poder da 
fala é uma autoridade quase mágica, pois objetiva e realiza seu discurso. Tem legitimidade de impor um sentido e um conteúdo a todos. Portanto, não existem discursos neutros", explica Setton (2001, p. 34) parafraseando parte da teoria de Pierre Bourdieu. Essa experiência é potencializada pela mídia eletrônica (especialmente a televisão) por que a possibilidade de feedback entre emissores e receptores da mensagem é praticamente nula.

Para finalizar, a apresentação de dois dados da pesquisa do Instituto Meta a respeito dos meios de comunicação mais confiáveis para buscar informações. Esses números serão importantes para comparação após a pesquisa e para a finalidade do uso da Internet.

\begin{tabular}{l|r|r|r|r|r}
\hline \hline \multirow{2}{*}{$\quad$ Acesso a Internet } & \multicolumn{4}{|c|}{ Classes de idade (anos) (\%) } & \multirow{2}{*}{ Total } \\
\cline { 2 - 5 } & 16 a 24 & 25 a 39 & 40 a 49 & 50 ou mais & \\
\hline Principal finalidade de utilização & & & & & \\
Estudo & 12,2 & 7,6 & 4,0 & 6,5 & 9,0 \\
Trabalho & 9,5 & 24,7 & 32,9 & 28,5 & 19,7 \\
Lazer & 62,9 & 37,2 & 30,4 & 27,6 & 46,3 \\
Informaçães & 15,2 & 30,3 & 32,7 & 37,5 & 24,8 \\
Não sabe & 0,2 & 0,2 & 0,0 & 0,0 & 0,2 \\
\hline Costuma ler jornais, blogs ou notícias & & & & & \\
Sim & 39,4 & 53,0 & 54,6 & 56,2 & 47,7 \\
Não & 60,6 & 47,0 & 45,4 & 43,8 & 52,3 \\
\hline Tamanhos amostrais por grupo & 2.116 & 1.906 & 610 & 419 & 5.532 \\
\hline \hline
\end{tabular}

Figura 3 - Principal finalidade de utilização da Internet Fonte: META, 2010, p. 33.

Apenas $24,8 \%$ dos entrevistados utilizam a Internet com a finalidade de buscar informações. Quase a metade do total, 46,3\%, utiliza a rede mundial com o objetivo lúdico, ou seja, voltado ao lazer. No entanto, esses são números relativos à utilização primária da Internet. Apesar de a finalidade ser o lazer, o número de pessoas que acessam jornais, blogs ou notícias na rede é de 47,7\%, tecnicamente o mesmo daqueles que não o fazem - 52,3\%. Embora haja um crescimento, ainda pode ser discutido o conteúdo das informações acessadas, mas esse não é o objetivo neste momento. De qualquer forma, o número daqueles que não utilizam a Internet para procurar informações é altíssimo. 


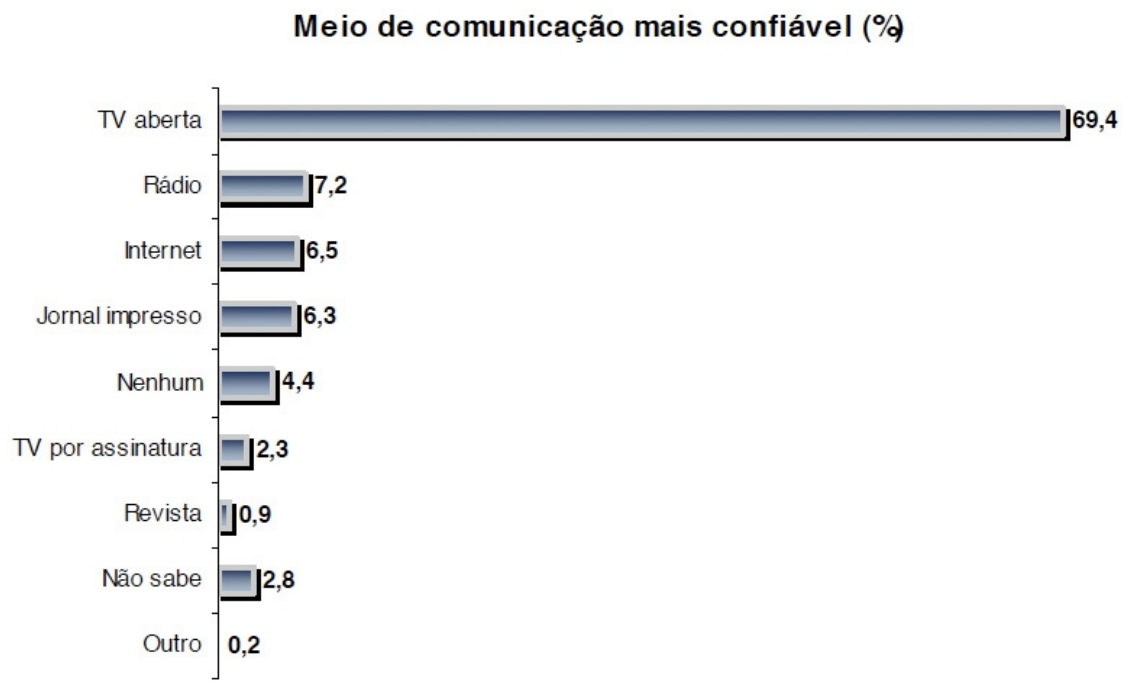

Figura 4 - Meio de comunicação mais confiável par buscar informações Fonte: META, 2010, p. 57.

O gráfico anterior, no entanto, demonstra a hegemonia da TV aberta em relação à confiança dos espectadores na hora de obter as informações. O percentual representa mais do que o dobro de todos os outros meios juntos. Não deixa de ser preocupante, já que isso cria - ou é criado por - o ambiente necessário para o desenvolvimento de uma área de influência gigantesca, que torna os receptores da informação bastante suscetíveis e dependentes das informações veiculadas nas emissoras de televisão de sinal aberto.

Os estudos das representações sociais criadas a partir dos meios de comunicação não são novos, mas, apesar disso, o subjetivismo das variantes sociais e a simples situação da relação entre entrevistado/pesquisador tende a criar uma barreira que dificulta a execução de estudos que tracem com propriedade o impacto da imprensa sobre a população. Em sua teoria Pierre Bourdieu constrói o conceito de habitus, que serve de base para o modelo do habitus comunicativo, também estudado pelo professor Clóvis de Barros Filho (2003).

O habitus é uma espécie de resposta automática do consciente receptor da informação. Trata-se de um processo subjetivo que cria uma mecânica de conforto e conveniência para a recepção das mensagens. Esse habitus é tão natural que as pessoas praticamente não se dão conta de sua existência. Uma pessoa que criou um habitus voltado para o liberalismo financeiro, ao receber a informação de uma possível estatização de empresas, desenvolve seu raciocínio de forma automática contra essa solução. Uma pessoa com um habitus marxista desenvolve um raciocínio diferente. 
Esse é um processo muito rápido e ocorre em praticamente todas as situações em que a comunicação está presente.

O habitus, portanto, funciona como uma espécie de catalisador para o processamento das mensagens recebidas. Ele não impossibilita que as pessoas pensem, mas cria uma espécie de inércia receptiva muito cômoda. Não há como ser diferente. Segundo o professor Fernando Hernandez (1998, p. 65), o mundo produziu mais informações nos últimos 30 anos do que nos últimos cinco mil. Mais de nove mil títulos de revistas são publicados a cada ano nos Estados Unidos e outros mil títulos de livros são divulgados por dia. Fisiologicamente, seria impossível raciocinar sobre cada informação de cada evento e ajustar cada uma delas a uma construção social individual. Por isso, as mensagens noticiosas acabam sendo recebidas e analisadas individualmente de forma muito superficial, fazendo com que as pessoas internalizem apenas os elementos mais evidentes da informação, sem buscar profundidade na análise.

\section{Metodologia}

O tamanho e a força da influência da mídia televisiva sobre a sociedade são, como foi possível observar, tecnicamente impossíveis de serem mensuradas. Mas não de serem constatadas, assim como não é impossível prever e verificar situações que podem causar ocultação de informação relevante ao receptor da notícia.

Para isso, tomou-se por base o noticiário Jornal Nacional, veiculado na Rede Globo - que, conforme dados apresentados anteriormente, é o mais assistido pela população. Foram destacadas todas as notícias do telejornal referente à Copa do Mundo FIFA. Esse foi o dia posterior à aprovação, pela Câmara dos Deputados, da Medida Provisória que institui o Regime Diferenciado de Contratações (RDC) para cidades e Estados que receberão obras de infraestrutura com o objetivo de receber partidas para a Copa do Mundo 2014 e as Olimpíadas. Não é difícil imaginar a polêmica entre oposição e situação no congresso nacional, e a repercussão da medida em meio à sociedade civil. E, logicamente, esse foi o assunto tratado durante a exibição do telejornal da Rede Globo. 
TRANSCRIÇÃO DA REPORTAGEM SOBRE A APROVAÇÃO DO RDC, VEICULADA NO JORNAL NACIONAL EM 16 DE JUNHO DE 2011.

Fátima Bernardes (estúdio)

A Câmara dos deputados aprovou o texto da Medida Provisória que altera as regras das licitações públicas para a Copa de 2014 e das Olimpíadas de 2016.

\section{Repórter Ari Peixoto (off)}

Para o Governo, as novas regras vão simplificar e dar mais rapidez à contratação das obras, já que pelo texto, a empresa vencedora da licitação seria responsável pela elaboração do projeto, a execução e a entrega da obra acabada.

Mas, um dos artigos foi questionado pela oposição: o que diz que o orçamento das obras só será fornecido após o encerramento da licitação. Para os oposicionistas, esse artigo facilitaria o superfaturamento e a corrupção.

Os governistas dizem que o sigilo sobre os valores que serão informados aos órgãos de fiscalização vai evitar a formação de cartel entre as empresas concorrentes.

O Ministério Público Federal criticou a aprovação do regime diferenciado de contratações e o procurador geral da República, Roberto Gurgel, considerou um absurdo o sigilo no orçamento dos projetos da Copa. O PPS informou que vai recorrer ao judiciário.

Entrevista Dep. Rubens Bueno (líder do PPS)

Nós vamos ao STF para que o Supremo Tribunal Federal indique claramente que essa é uma lei inconstitucional.

\section{Repórter Ari Peixoto (off)}

O relator defendeu a proposta.

Dep. José Guimarães

É uma lei que dá celeridade e estabelece um rigor muito grande no processo fiscalizatório por parte do Tribunal de Contas da União. O TCU é parceiro na construção dessa alternativa, porque nós queremos realizar as obras da Copa.

\section{Repórter Ari Peixoto, de Brasília (Passagem)}

Especialistas em Direito Administrativo dizem que o sigilo em licitações de obras públicas só é justificável em casos excepcionais: quando haja risco à segurança da sociedade e do Estado. Segundo eles, em qualquer outra situação, o sigilo é inconstitucional.

Entrevista Mamede Said (especialista Direito Administrativo - UnB)

Mesmo que o Governo queira agilizar as obras com vista à Copa, não se pode jogar por terra toda essa tradição que se construiu na nossa legislação, que vem de muito tempo, e que visa resguardar o interesse público, em primeiro lugar, e a transparência no manuseio da verba pública.

\section{Fátima Bernardes (estúdio)}

Apesar da aprovação, os deputados ainda vão votar os destaques que os deputados da oposição incluíram nas novas regras.

Título: Regras de licitações para obras da Copa 2014 e das Olimpíadas de 2016 são alteradas.

Link para acesso: $\mathrm{http} / / \mathrm{g} 1$.globo.com/videos/jornal-nacional/v/regras-de-licitacoes-para-obras-da-copa-2014-edas-olimpiadas-de-2016-sao-alteradas/1538554/\#/Edições/20110616/page/1

Data de veiculação: 16 de junho de 2011.

Tempo: 2'10"

Não se trata de uma simples menção de bancada, mas de uma reportagem bastante abrangente sobre o fato em questão. A proposta, agora, é comparar as informações veiculadas pelo Jornal Nacional com outras veiculadas por meios de comunicação eletrônicos, deixando de lado as informações coincidentes (interseções) e analisando as informações que não constam na veiculação do telejornal (extrasseções), mas que possuem relevância significativa para a construção de uma opinião fomentada 
por um número maior de informações. Evidentemente, serão analisadas apenas notícias veiculadas até o horário de início do telejornal. Sendo assim, todas as informações publicadas após as 20h40m de 16 de junho de 2011 serão descartadas. Os sites em que foram obtidos os dados comparativos são: ESPN Brasil, Folha de São Paulo e Terra.

\section{Análise dos resultados}

No total, foram identificadas e analisadas 23 reportagens, sendo 6 (seis) no Terra, 4 (quatro) na Folha.com e 13 (treze) no site da ESPN Brasil. Considerando que, entre os três, o site da ESPN é o único com foco exclusivamente voltado a assuntos relacionados ao esporte, era esperado que tivesse um conteúdo maior de notícias referentes ao assunto.

Das reportagens analisadas, na ESPN foram constatadas 5 (cinco) informações referentes à Copa do Mundo 2014 totalmente alheias ao assunto da aprovação da Medida Provisória que alterou o RDC, exibida pelo Jornal Nacional da Rede Globo. Duas delas eram correlacionadas e tratavam sobre a greve dos funcionários do Mineirão, que não chegaram a acordo com a construtora. O início das obras do estádio do Corinthians, acompanhado por uma comissão de deputados e fiscais do Tribunal de Contas, o aniversário de 61 anos do Maracanã, comemorado nas obras de restauração para a Copa, onde foi anunciada a redução dos valores orçamentários da obra, também estiveram presentes na pauta, assim como as declarações do Ministro dos Esportes britânico de que o país não será mais candidato a sediar uma Copa do Mundo enquanto não houver uma política de transparência na FIFA.

A quantidade de notícias da mesma natureza da veiculada pelo Jornal Nacional, mas com informações complementares, somou 2 (duas) ocorrências. Em uma delas, o chefe-de-gabinete da Secretaria de Alto Rendimento do Ministério dos Esportes explicou a metodologia adotada pelas construtoras para obtenção de lucros mais altos nas licitações - prática que o Governo tenta combater e que foi a justificativa para o RDC. Na outra, veiculada pelo blog do jornalista Mauro Cezar Pereira, da ESPN, consta a relação nominal de todos os deputados que foram favoráveis à Medida Provisória.

Nas outras 4 (quatro) notícias veiculadas pelo site da ESPN não houve informação complementar ao que foi veiculado pelo Jornal Nacional.

No site do portal Terra, foram registrados 4 (quatro) notícias sem relação direta com a veiculada pelo Jornal Nacional. Mas 3 (três) delas bastante semelhantes às que foram veiculadas pela ESPN e tratavam da greve dos funcionários do Mineirão, 
aniversário do Maracanã e redução dos valores orçamentários. Outra matéria noticiava a apuração, pelo Tribunal de Contas da União e os deputados estaduais, de superfaturamento nas obras do Mineirão, com a constatação do pagamento de diversos serviços que sequer haviam sido executados.

As outras duas notícias analisadas não possuíam informações complementares ao que foi exibido pelo noticiário da Rede Globo.

No caso da Folha.com, apenas 1 (uma) das notícias veiculadas trouxe informação sem relação ao que foi veiculado pelo telejornal: trata sobre a decisão dos deputados de investigarem a pressão feita pelos agentes da FIFA sobre as cidades-sede, de modo que favoreçam seus parceiros. Nas demais, não foram constatadas informações relevantes complementares, apenas entrevistas com pessoas diferentes, cujo discurso pouco se diferenciava do que foi exibido pelo Jornal Nacional.

O objetivo dessa pesquisa foi mostrar que existem informações que transitam além daquilo que é noticiado. Neste caso, foi utilizado como base um dos assuntos em pauta no telejornal abordado. E ainda assim, diversas outras informações relevantes sobre a mesma editoria ficaram à margem da massa de telespectadores, ficando restritas à Internet. O cenário torna-se ainda mais intenso quando consideramos assuntos que sequer entraram na pauta do noticiário, o que caracteriza um padrão de omissão ainda mais relevante, por que sequer é lançado ao debate público.

\section{Considerações finais}

Considerando o caso de análise previamente apresentado e combinando esses dados com os dados da pesquisa desenvolvida pelo Instituto Meta, percebe-se que uma enorme faixa da população depende estritamente das informações recebidas pelo noticiário televisivo. E o Jornal Nacional lidera com folga a preferência dos leitores, atingindo 56,4\%. (META, 2010, 21). Diante disso, é bastante provável que uma parte expressiva da população literalmente não tomou ciência da greve dos funcionários das obras do Mineirão, tampouco das denúncias de superfaturamento que começaram a pipocar em torno do mesmo.

A ausência dessas informações no noticiário hegemônico viabiliza a produção de representações sociais exclusivamente construídas a partir de uma realidade determinada pela pauta de veiculação das notícias. Mesmo nos casos em que há a possibilidade de buscar outras fontes de informação na rede virtual, não há qualquer garantia de que isso ocorra. Ainda assim, mesmo entre aqueles que buscam as 
informações em sites de notícias, não se pode afirmar que o site de preferência abordará o assunto em questão, já que há uma pluralidade de assuntos que compõem a pauta também na Internet.

Transportando esse mesmo padrão para uma situação em que o assunto em pauta não seja a Copa do Mundo FIFA 2014, mas o período eleitoral, temos um quadro bastante singular. Por que se um dos preceitos da democracia representativa é o acesso da população às informações, e a população não tem acesso a todas as informações, conclui-se que tomará sua escolha a partir de uma opinião formada apenas por fragmentos do assunto em questão. Uma massa de eleitores virtualmente dependentes e restritos a aquilo que é veiculado pelas emissoras de televisão aberta. E mais, imputando essa situação nos conceitos de habitus de comunicação, percebe-se a existência de uma considerável fatia de receptores que sequer raciocina sobre as informações transmitidas pelos meios de comunicação de massa.

O questionamento não coloca em evidência apenas a dúvida de quem questiona. Ele põe em cheque o próprio conhecimento de causa de quem está sendo questionado. Não é à toa que o questionamento é causa e efeito de todo pragmatismo em ruína. O "por que?” possui uma força avassaladora nos macaquinhos que não aceitam mais apanhar de seus companheiros por desejarem alcançar as bananas. E possui o mesmo efeito na sociedade humana. O habitus parece uma peça de alicerce do pragmatismo social. Talvez como um átomo para a biologia. $\mathrm{O}$ autoquestionamento ou $\mathrm{o}$ questionamento social, longe de serem vistos como constrangedores, devem ser observados com interesse. Não se constrói qualquer cidadania sobre certezas absolutas. 


\section{Referências}

BARROS FILHO, Clóvis de \& MARTINO, Luiz Mauro. O habitus na comunicação. São Paulo: Paulus, 2003.

CHOMSKY, Noam. Controle da mídia: os espetaculares efeitos da propaganda. Rio de Janeiro: Graphia, 2003. HERNANDEZ, Fernando. Cultura Visual, mudança educativa e projeto de trabalho. Porto Alegre: Artmed, 1998.

LUHMANN, Niklas. A realidade dos meios de comunicação. São Paulo: Paulus, 2005. MCCOMBS, Malcolm; SHAW, Donald. The agenda-setting function of mass media. In: Public Opinion Quaterly. Vol. 36, $\mathrm{n}^{\mathrm{o}}$ 2, p. 176-87. Nova York, 1972. META, Instituto de Pesquisas. Hábitos de informação e formação de opinião da população brasileira.

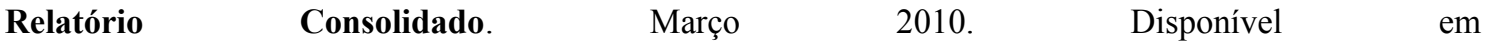
$<$ http://www.midiarj.org.br/sites/default/files/Pesquisa\%20SECOM\%202010.pdf $>$ Acesso em 20 fev 2011.

SETTON, Maria da Graça Jacintho. Indústria Cultural: Bourdieu e a Teoria Clássica. In: Comunicação \& Educação. São Paulo, $\quad$ n. $\quad 22, \quad$ set/dez 2001, $\quad$ pp. TRAQUINA, Nelson. Teorias do Jornalismo: porque as notícias são como são. Vol. I. $2^{\text {a }}$ ed. Florianópolis: 


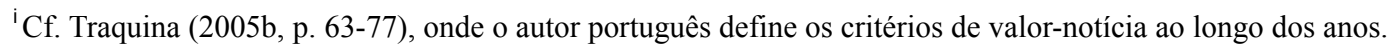

ii Cf. Chomsky (2003, p. 9-35). O jornalista Walter Lippmann também foi fundamental para a concepção do modelo democrático atual.

iii Todos os dados são reproduzidos a partir dos resultados divulgados em META, 2010.

Este artigo e todo o conteúdo da Estudos em Jornalismo e Mídia estão disponíveis em http://www.periodicos.ufsc.br/index.php/jornalismo/index

Estudos em Jornalismo e Mídia está sob a Licença Creative Commons. 